\title{
FACULTY PERCEPTIONS OF PEDAGOGICAL BENEFITS OF WEB 2.0 TECHNOLOGIES AND VARIABLES RELATED TO ADOPTION
}

\author{
Pamela A. Dupin-Bryant, Utah State University, pam.dupin-bryant@usu.edu
}

\begin{abstract}
In recent years, a variety of Web 2.0 technologies have surfaced as a means for collaboration and information sharing. While countless students and businesses have embraced these emerging technologies, information systems (IS) educators may not be applying these technologies in their classrooms. The purpose of this paper is to initiate the design of an on-going research study that will explore current role of Web 2.0 technologies, specifically wikis, blogs, and social networking sites in information systems classroom instruction; assess faculty perceptions of pedagogical benefits of Web 2.0 applications; describe current faculty use of Web 2.0 technologies; and how to adopt these technologies with informed decisions. This study should promote discussion on whether or how these emerging technologies can influence the way we educate future IS professionals. Results may also prove helpful to educators in implementing Web 2.0 technologies into the IS curriculum and to help prepare students to utilize these collaborative tools in business settings.
\end{abstract}

Keywords: Web 2.0, Wikis, Blogs, Social Networking, IS Pedagogy, and Technology Adoption

\section{INTRODUCTION}

Over the past several decades, Internet technologies such as e-mail and course management systems have emerged as common tools for enhancing the learning process in most higher education disciplines [15]. In recent years, a variety of Web 2.0 technologies have surfaced as a means for collaboration and information sharing. While students and businesses have embraced these emerging technologies such as wikis, blogs, and social networks [7, 10, 19], information systems (IS) educators may not be applying these technologies in their classrooms. Kane and Fichman [13] suggest Web 2.0 tools have revolutionized business practices yet "we have engaged in comparatively little discussion on whether or how these emerging technologies can influence the way we practice our own craft as academicians." With Web 2.0 technologies students can create collective knowledge through social interactions [15] thus enhancing the IS curriculum. Although adopting innovative Web 2.0 technologies may provide closer connections to students and promote knowledge sharing and creation, usage should be based on solid theoretical underpinnings $[14,18]$.

IS researchers and educators alike have advocated for the integration of these collaborative tools to improve the teaching and learning process $[5,9,10,12,13,16,18]$. Whether "one's passion as an IS academic is personally trying out Web 2.0 technologies in innovative ways...[or] watching how the use of Web 2.0 technologies fundamentally changes our theories" [14], Web 2.0 technologies will continue to enable the IS discipline [13, 18]. Yet, anecdotal evidence and the lack of empirical studies in this area suggests limited use of Web 2.0 technologies in formal higher education IS coursework. Te'eni [18] suggests many IS educators have experimented in class with Web 2.0 technologies. Yet, research describing current IS faculty use of Web 2.0 technologies and perceptions of pedagogical benefits is lacking.

The purpose of this paper is to initiate the design of an on-going research study that will 1) explore current role of Web 2.0 technologies, specifically wikis, blogs, and social networking sites in information systems classroom instruction; 2) assess faculty perceptions of pedagogical benefits of Web 2.0 applications; 3 ) describe current faculty use of Web 2.0 technologies; and 4) how to adopt these technologies with informed decisions. Research questions include: (a) To what extent do IS faculty currently use Web 2.0 technologies to facilitate classroom learning? (b) What are faculty perceptions of the pedagogical benefits of wikis? (c) What are faculty perceptions of the pedagogical benefits of social networking sites? (d) What are faculty perceptions of the pedagogical benefits of blogs? and (e) What variables best predict IS faculty's decision to adopt Web 2.0 technologies? This study seeks to 


\section{Issues in Information Systems}

Volume 13, Issue 1, pp. 258-263, 2012

promote discussion amongst IS educators on whether or how these emerging technologies can influence the way we educate future IS professionals. Results may also prove helpful to educators in implementing Web 2.0 technologies into the IS curriculum and to help prepare students to utilize these dynamic, collaborative tools in business practices. This work in progress paper is organized as follows. Theoretical background and research hypotheses are presented along with the research model. Since this paper outlines research in progress a detailed methodology section is presented prior to concluding remarks.

\section{THEORETICAL BACKGROUND AND HYPOTHESES}

This study seeks to investigate behavioral beliefs of the individual in explaining Web 2.0 technology attitude, intention, and actual usage/behavior. Technology adoption can be conceptualized as a behavior. Behavioral intention research is often studied holistically using comprehensive models. Yet, looking at intention to adopt Web 2.0 technologies in this manner can be crippling. Theorists suggest information systems research focusing on behavioral intention should refine and tailor a theory to fit a specific research context [11]. A recent study on Web 2.0 technology adoption customized an accepted behavioral intention model and concentrated on a subset of constructs [1].

Ajzen [2] developed a behavioral intention model that is widely cited and tested empirically. This study focuses on the attitude component of Ajzen's Theory of Planned Behavior (TPB). Behavioral beliefs according to the TPB refer to the beliefs about consequences of a particular behavior; they "produce a favorable or unfavorable attitude toward the behavior" [3]. This study focuses on behavioral beliefs related to perceived usefulness. As with Ajzen's comprehensive model [4], this model suggests attitude toward the behavior leads to behavioral intention. Intention is defined as the cognitive representation of an individual's subjective probability to perform a given behavior and in Ajzen's model [4], intention is assumed to be the immediate antecedent to behavior.

Figure 1 summarizes the research model. Each variable included in the research model, as antecedents of technology adoption, are described below along with associated research hypotheses. Hypotheses are stated in alternative form.

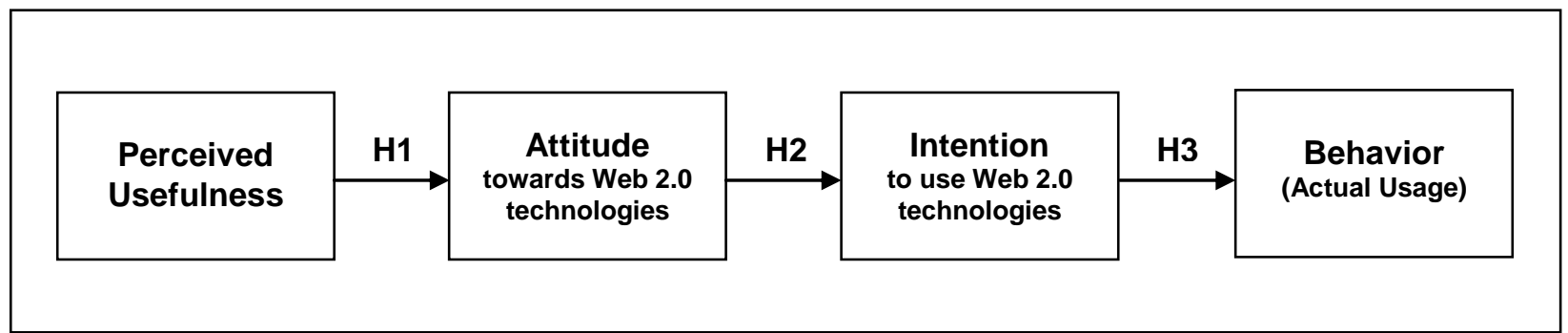

Figure 1. Research Model

\section{Perceived Usefulness}

Derived from the word useful (i.e. capable of being used advantageously), Davis [6] defined perceived usefulness as the degree to which a person believes that using a particular system or technology will improve performance. Perceived usefulness of using Web 2.0 technologies is defined as "the extent to which faculty members believe that using Web 2.0 will enhance their effectiveness in the classroom" [1]. In relationship to Web 2.0 technologies, a recent study looked at perceived usefulness. Ajjan and Hartshorne [1] found a significant positive relationship between perceived usefulness and attitude toward Web 2.0 technologies. Relative to the general TPB, Taylor and Todd [17] decomposed the attitude component to include perceived usefulness as an antecedent to attitude. This study will explore the relationship between perceived usefulness and attitude toward Web 2.0 technologies. 


\title{
Issues in Information Systems
}

Volume 13, Issue 1, pp. 258-263, 2012

Hypothesis la (H1): The greater an individual perceives the usefulness of wikis, the more favorable his or her attitude is towards usage of wikis.

Hypothesis $1 b(\mathrm{H1})$ : The greater an individual perceives the usefulness of social networking sites, the more favorable his or her attitude is towards usage of social networking sites.

Hypothesis 1c $(\mathrm{Hl})$ : The greater an individual perceives the usefulness of blogs, the more favorable his or her attitude is towards usage of blogs.

\begin{abstract}
Attitude
The theory of planned behavior contends that attitude toward the behavior leads to behavioral intention [4]. Attitude in regards to Web 2.0 technology is defined as a psychological tendency of evaluating the technology and generating certain favorable or unfavorable responses. A recent study supports the assertion that attitude towards Web 2.0 technologies is a determinant of intention to use the technology [1]. This study will build upon this work and explore the relationship between attitude towards Web 2.0 technologies and intention to use these technologies.
\end{abstract}

Hypothesis $2 a(\mathrm{H} 2)$ : The more favorable an individual's attitude is toward wikis, the greater his or her intention will be to use wikis.

Hypothesis $2 b(\mathrm{H} 2)$ : The more favorable an individual's attitude is toward social networking sites, the greater his or her intention will be to use social networking sites.

Hypothesis 2c (H2): The more favorable an individual's attitude is toward blogs, the greater his or her intention will be to use blogs.

\section{Intention}

The theory of planned behavior posits intention is the most important determinant factor in predicting actual behavior; "given a sufficient degree of actual control over the behavior, people are expected to carry out their intentions when the opportunity arises....Intention is thus assumed to be the immediate antecedent of behavior" [2]. A perfect relationship between intention and actual behavior does not exist; yet intention is considered a proximal measure of behavior [8]. In a recent study of Web 2.0 technologies to supplement in-class learning by higher education faculty, a very significant relationship was found between intention and actual behavior [1]. This study will explore the relationship between IS faculty intention to employ Web 2.0 technologies in their courses and actual usage/behavior.

Hypothesis $3 a(H 3)$ : The more favorable an individual's intention to use wikis, the greater his or her actual behavior will be to use wikis.

Hypothesis $3 b(H 3)$ : The more favorable an individual's intention to use social networking sites, the greater his or her actual behavior will be to use social networking sites.

Hypothesis 3c(H3): The more favorable an individual's intention to use blogs, the greater his or her actual behavior will be to use blogs.

\section{RESEARCH METHODOLOGY}

This study seeks to gather evidence from information systems faculty who teach at the University level that will lead to general conclusions about faculty perceptions of the pedagogical benefits of Web 2.0 applications, current faculty use of Web 2.0 technologies, and relationships between perceived usefulness, attitude, intention, and behavior using a descriptive and correlational, quantitative research design. 


\section{Issues in Information Systems}

Volume 13, Issue 1, pp. 258-263, 2012

\section{Sampling Procedure}

Participants will be randomly selected from information systems faculty registered on the Association for Information Systems Faculty Directory (http://m360.aisnet.org/frontend/search.aspx?cs=1082). The information systems faculty (i.e. 8,902) listed on this site will comprise the accessible population. A sample size of 200 was determined for this study. The sample size is based on power analysis, by reviewing methodologies of related research, and by consulting a minimum total sample size table. To insure the sample size will be reached the study will assume a 50\% response rate and thus approximately 400 individuals will be randomly selected to participate.

\section{Data Collection}

Participants will be solicited via email from the aforementioned faculty directory. Selected participants will be asked to complete a web-based survey which includes demographic information and items related to Web 2.0 technologies. Since the sample frame was carefully selected and based on relevance to the research goals, the anticipated salience of the survey's content to respondents is high. Information about the faculty who completed the survey will be provided to make it easier to identify the appropriate group to whom inferences apply. The subjects will not identify themselves on the questionnaires. The responses will be anonymous to encourage participation. However, since there are significant issues associated with Web-based survey research related to privacy and security, a third-party Web-based data collection tool will be used. This study will use SurveyMonkey to assure the security of information transmitted over the Web. SurveyMonkey is a reputable data collection tool that employs multiple layers of security to insure data will remain private and secure.

\section{Instrumentation}

An online questionnaire will be used to collect data for this study. The instrument was carefully developed based on Ajzen's Theory of Planned Behavior [2, 3, 4] and by following the recommendations in Constructing Theory of Planned Behaviour Questionnaires: Manual for Researchers [8]. Items will be interspersed prior to data collection and $25 \%$ of the survey questions will be reverse-scaled in order to protect against positive response bias. The survey items use 7-point likert scales. Items to measure perceived usefulness (strongly disagree to strongly agree) were generated based on the perceived usefulness scale used by Ajjan and Hartshorne [1]. The attitude scale was developed based on the scales of Ajjan and Hartshorne [1] and in accordance with the TPB instrument development manuals [3, 8]. The behavioral intention scale was developed using scales designed by Ajjan and Hartshorne [1]. The actual usage/behavior scale was developed in accordance with the TPB instrument development manuals [3, 8]. Appendix A lists the items in each scale.

\section{Data Analysis}

Various techniques will be used to analyze the data, including descriptive statistics, reliability analysis, and factor analysis to assess construct validity. Correlational analysis will be used to investigate relationships between the behavioral belief - perceived usefulness, attitude, intention, and behavior (Hypotheses 1-3). A card sort has been conducted on ten respondents to test face validity. Results will be triangulated with exploratory factor analysis performed on approximately fifty faculty members participating in a pilot test.

\section{CONCLUSIONS}

This study promises to make several important contributions to theory, practice, and education. Kane and Fichman [13] suggests "IS researchers have spent considerable time exploring the impact and implications of these [Web 2.0] tools in organizations, but we argue those same researchers have not spent sufficient time considering whether and how these new technologies may provide opportunities for us to reform our core practices of research, review, and teaching." This study will contribute new knowledge to the field and may help enhance the educational quality of IS programs. This study should promote discussion amongst IS educators on whether or how these emerging technologies can influence the way we educate future information systems professionals. Results may also prove 


\section{Issues in Information Systems}

Volume 13, Issue 1, pp. 258-263, 2012

helpful to educators in implementing Web 2.0 technologies into the IS curriculum and to help prepare students to utilize these Internet-based collaborative tools in business practices.

\section{REFERENCES}

1. Ajjan, H., \& Hartshorne R. (2008). Investigating faculty decisions to adopt web 2.0 technologies: Theory and empirical tests, Internet and Higher Education, 11, 71-80.

2. Ajzen, I. (1991). The theory of planned behavior, Organizational Behavior \& Human Decision Processes, $50(2), 179-211$.

3. Ajzen, I. (2006a). Constructing a TPB questionnaire: Conceptual and methodological considerations. Available: http://www.people.umass.edu/aizen/pdf/tpb.measurement.pdf.

4. Ajzen, I. (2006b). Behavioral interventions based on the theory of planned behavior. Available: http://people.umass.edu/aizen/pdf/tpb.intervention.pdf.

5. Brown, J. S., \& Adler, R. P. (2008). Minds on fire: Open education, the long tail, and learning 2.0, Educause Review, 43(1), 16-32.

6. Davis, F. (1989). Perceived usefulness, perceived ease of use, and user acceptance of information technology, MIS Quarterly, 13(3), 319-339.

7. De Hertogh, S., Viaene, S., \& Dedene, G. (2011). Governing web 2.0, Communications of the ACM, 54(3), 124130.

8. Francis, J., Eccles, M., Johnston, M., Walker, A., Grimshaw, J., Foy, R., Kaner, E., Smith, L., \& Bonnetti, D. (2004). Constructing questionnaires based on the theory of planned behavior, Centre for Health Services Research, New Castle, United Kingdom.

9. Gooding, J. (2007). Web 2.0: A vehicle for transforming education, International Journal of Information and Communication Technology Education, 4(2), 44-53.

10. Granitz, N., \& Koernig, S. K. (2011). Web 2.0 and marketing education: Explanations and experiential applications, Journal of Marketing Education, 33(1), 57-72.

11. Harrison, D., Mykytyn, P., \& Riemenschneider, C. (1997). Executive decisions about adoption of information technology in small business: Theory and empirical tests, Information Systems Research, 8, 171-194.

12. Huang, C. D., \& Behara, R. S. (2007). Outcome driven experiential learning with web 2.0, Journal of Information Systems Education, 18, 329-336.

13. Kane, G. C., \& Fichman, R. G. (2009). The shoemaker's children: Using wikis for information systems teaching, research, and publication, MIS Quarterly, 33(1), 1-17.

14. Majchrzak, A. (2009). Comment: Where is the theory in wikis? MIS Quarterly, 33(1), 18-21.

15. Maloney, E. J. (2007). What Web 2.0 can teach us about learning, Chronicle of Higher Education, 25(18), B26.

16. Sendall, P., Ceccucci, W., \& Peslak, A. R. (2008). Web 2.0 matters: An analysis of implementing Web 2.0 in the classroom, Information Systems Education Journal, 6, 1-17.

17. Taylor, S., \& Todd, P. (1995). Understanding information technology usage: A test of competing models, Information Systems Research, 6(2), 144-176.

18. Te'eni, D. (2009). Comment: The wiki way in a hurry-The ICIS anecdote, MIS Quarterly, 33(1), 20-22.

19. Watson, B. P. (2008). Full speed ahead, CIO Insight, 93, 40-45.

\section{APPENDIX A. MEASURES}

\begin{tabular}{|l|l|}
\hline \multicolumn{2}{|l|}{ Measurement Items -7 Point Likert Scales } \\
\hline Perceived Usefulness (Strongly Agree to Strongly Disagree) \\
\hline PU1 & Using Wikis will help my students learn more about the subject \\
\hline PU2 & Using Wikis will improve students' satisfaction with the course \\
\hline PU3 & Using Wikis will improve students' grades \\
\hline PU4 & Using Wikis will increase student-faculty interaction \\
\hline PU5 & Using Wikis will increase student-student interaction \\
\hline
\end{tabular}




\section{Issues in Information Systems}

Volume 13, Issue 1, pp. 258-263, 2012

\begin{tabular}{|c|c|}
\hline PU6 & Using Social Networking Sites will help my students learn more about the subject \\
\hline PU7 & Using Social Networking Sites will improve students' satisfaction with the course \\
\hline PU8 & Using Social Networking Sites will improve students' grades \\
\hline PU9 & Using Social Networking Sites will increase student-faculty interaction \\
\hline PU10 & Using Social Networking Sites will increase student-student interaction \\
\hline PU11 & Using Blogs will help my students learn more about the subject \\
\hline PU12 & Using Blogs will improve students' satisfaction with the course \\
\hline PU13 & Using Blogs will improve students' grades \\
\hline PU14 & Using Blogs will increase student-faculty interaction \\
\hline PU15 & Using Blogs will increase student-student interaction \\
\hline \multicolumn{2}{|r|}{ Attitude (Strongly Agree to Strongly Disagree) } \\
\hline AT1 & Wikis are a useful teaching tool \\
\hline AT2 & The advantages of using wikis as a teaching tool outweighs the disadvantages \\
\hline AT3 & Using wikis as a teaching tool is a good idea \\
\hline AT4 & Social Networking Sites are a useful teaching tool \\
\hline AT5 & The advantages of using Social Networking Sites as a teaching tool outweighs the disadvantages \\
\hline AT6 & Using Social Networking Sites as a teaching tool is a good idea \\
\hline AT7 & Blogs are a useful teaching tool \\
\hline AT8 & The advantages of using blogs as a teaching tool outweighs the disadvantages \\
\hline AT9 & Using blogs as a teaching tool is a good idea \\
\hline \multicolumn{2}{|c|}{ Intention (Strongly Agree to Strongly Disagree) } \\
\hline IN1 & I intend to use wikis in my courses \\
\hline IN2 & I expect to use wikis as a teaching tool in the future \\
\hline IN3 & I will likely add wikis as a teaching tool to my courses in the future \\
\hline IN4 & I intend to use Social Networking Sites in my courses \\
\hline IN5 & I expect to use Social Networking Sites as a teaching tool in the future \\
\hline IN6 & I will likely add Social Networking Sites as a teaching tool to my courses in the future \\
\hline IN7 & I intend to use blogs in my courses \\
\hline IN8 & I expect to use $b \log s$ as a teaching tool in the future \\
\hline IN9 & I will likely add blogs as a teaching tool to my courses in the future \\
\hline \multicolumn{2}{|r|}{ Actual Usage/Behavior (Strongly Agree to Strongly Disagree) } \\
\hline AU1 & I currently use wikis in my courses \\
\hline AU2 & I have used wikis as a teaching tool in my courses this past year \\
\hline AU3 & I have added wikis as a teaching tool to my courses in the past year \\
\hline AU4 & I currently use Social Networking Sites in my courses \\
\hline AU5 & I have used Social Networking Sites as a teaching tool in my courses this past year \\
\hline AU6 & I have added Social Networking Sites as a teaching tool to my courses in the past year \\
\hline AU7 & I currently use blogs in my courses \\
\hline AU8 & I have used blogs as a teaching tool in my courses this past year \\
\hline AU9 & I have added blogs as a teaching tool to my courses in the past year \\
\hline
\end{tabular}

